\title{
Overweight, obesity and perceptions about body weight among primary schoolchildren in Dar es Salaam, Tanzania
}

\author{
ROSE N.M. MPEMBENI $1^{*}$, ALFA J. MUHIHI ${ }^{2,3}$, MWANAMKUU MAGHEMBE ${ }^{1}$, DAVIS NGARASHI', BENJAMIN \\ LUJANI', OMARY CHILLO', SULENDE KUBHOJA ${ }^{1}$, AMANI ANAELI ${ }^{1}$ and MARINA A. NJELEKELA ${ }^{1},{ }^{4}$ \\ ${ }^{1}$ Muhimbili University of Health and Allied Sciences, P.O. Box 65001, Dar es Salaam, Tanzania \\ ${ }^{2}$ Clinical Trial Unit, Africa Academy for Public Health, Dar es Salaam, Tanzania \\ ${ }^{3}$ Ifakara Health Institute, P.O. 53, Ifakara, Tanzania \\ ${ }^{4}$ Muhimbili National Hospital, P.O. Box 65000 Dar es Salaam, Tanzania
}

\begin{abstract}
The increasing prevalence of overweight and obesity among children has become a public health concern both in developing and developed countries. Previous research studies have shown that favourable perception of one's body weight is an important factor in weight control. This study determined prevalence of overweight and obesity and assessed perception about body weight among primary schoolchildren in Dar es Salaam, Tanzania. In this cross sectional study, nine schools were selected randomly from a list of all primary schools in Dar es Salaam. A structured questionnaire was used to collect data on socio-demographic characteristics and lifestyle information including perception about body weight. Height and weight were measured following standard procedures. Chi-square tests and multiple logistic regressions were used to determine factors which influence perceptions about body weight. A total of 446 children were included into the study. The mean body mass index (BMI) was $16.6 \pm 4.0 \mathrm{~kg} / \mathrm{m2}$ (16.1 \pm 4.0 for males and $17.0 \pm 4.0$ for females). Prevalence of overweight and obesity was $9.8 \%$ and $5.2 \%$, respectively. The prevalence of overweight and obesity was significantly higher among girls, $13.1 \%$ and $6.3 \%$ compared to boys with $6.3 \%$ and $3.8 \%$ overweight and obese respectively $(P=0.0314)$. Overall, the prevalence of overweight and obesity was $15.0 \%(10.1 \%$ among boys and $19.4 \%$ among girls). One-third (33.3\%) of the children perceived their body weight as overweight or obese. Among overweight and obese children, $35.4 \%$ had unfavourable perception of their body weights. There was a statistically significant difference between perceived body weight and actual body weight as indicated by $\mathrm{BMI}$ for both boys and girls $(\mathrm{P}<0.05)$. Age of the child (AOR=0.55 95\% $\mathrm{Cl} 0.36-0.85)$ and area of residence ( $C O R=0.6495 \% \mathrm{Cl}$ 0.44-0.95) were found to be significant predictors of favourable perception of one's body weight. In conclusion, the prevalence of overweight and obesity is not very high in this population. However over a third of overweight and obese children, had unfavourable perception of their body weights. We recommend targeted educational programmes about overweight and obesity and the associated health effects in order to instil a behaviour of self consciousness on overweight and obesity among children in Tanzania.
\end{abstract}

Keywords: overweight, obesity, body weight, perceptions, schoolchildren, Tanzania

\section{Introduction}

The increasing prevalence of overweight and obesity in children has become a public health concern worldwide. In 2010, 43 million children were estimated to be overweight and obese worldwide, out of whom, 35 million (81.4\%) were from developing countries (De Onis et al., 2010). In 2010, the worldwide prevalence of childhood overweight and obesity was $6.7 \%$ and is expected to reach $9.1 \%$ in 2020. In Africa, the estimated prevalence was $8.5 \%$ and is expected to reach $12.7 \%$ in 2020 (De Onis et al., 2010).

Few studies have been conducted on the prevalence of obesity among primary schoolchildren in Tanzania (Chillo et al., 2009; Kafyulilo \& Mafumiko 2010; Mosha \& Fungo 2010). However, none of these assessed the perception about body weight. Favourable perception of

\footnotetext{
*Correspondence: Rose Mpembeni; E-mail: rcmpembeni@gmail.com
} 
one's own weight is important for weight control behaviour (Wang et al., 2009) and probably more importantly among children and adolescents (Smolak, 2004). Perception about body weight is influenced by several factors including culture and ethnicity (Paeratakul et al., 2002; Gillum \& Sempos 2005). Western culture has a prevailing perception that low body weight is attractive (Nichter \& Nichter, 1991) and is preferred among females (Emslie et al., 2001). In developing countries particularly in Africa, overweight and obesity are preferred culturally, because overweight or obese persons are perceived as healthier than those who are of normal weight although the trend is shifting among people of higher class (Khawaja \& Afifi-Sowed, 2004). As children and adolescents experience physical changes in their bodies at puberty, they become more concerned with their body shape. Boys tend to be more concerned with their chest, shoulders and arms, while girls become more concerned with hips, thighs and legs(Vander Wal \& Thelen, 2000). In addition to sociocultural factors, the HIV pandemic in Tanzania has greatly impacted on peoples' perception about thin body weight with most people preferring to look overweight or obese so as to avoid being suspected of having HIV/AIDS (Ezekiel et al., 2009).

Studies among adults have shown that women overestimate and men underestimate their weight (Wardle \& Griffith 2001; Emslie et al., 2001; Inoue et al., 2007). Our previous study among middle-aged adults in Dar es Salaam also showed that a higher proportion of women perceived their weight as obese compared to men (Muhihi et al., 2012). A recent study among children and teenagers has indicated a similar pattern of more girls perceiving themselves as more overweight/obese, and consequently tend to lose weight than boys (Darshini \& Rajeshi, 2013).

Although, they cannot discriminate between body size being misperceived, verbal description methods with scale ranging from "very underweight" to "very overweight"( Wardle \& Marsland, 1990; Brener et al., 2004; Johnson et al., 2008) have been widely used in the assessment of body weight among children and adults. To complement verbal description methods, body images with known sizes are now available for assessment of body size among children (Truby \& Paxton, 2002, 2008). The present study used verbal description methods to investigate perceptions of body size in comparison with actual Body Mass Index (BMI) in a representative sample of primary schoolchildren in Dar es Salaam, Tanzania.

\section{Materials and Methods}

\section{Study design, site and participants}

This cross-sectional study was conducted among children aged 6-17 years recruited from three districts of Ilala, Kinondoni and Temeke in Dar es Salaam City, Tanzania. A sampling frame of all public and private schools in Dar es Salaam was obtained from the district education authorities. A two stage cluster sampling was used to select schools to be involved in the study. Selection was made to ensure equal representation from both urban and rural settings of Dar es Salaam. Within each selected school one class (from class 1-7) was randomly selected and all children from the selected class and their parents/guardians were invited to participate into the study. Based on the criteria set by Dar es Salaam Region authority, the schools were categorized as urban if located within $15 \mathrm{~km}$ radius from the city centre. Any school more than $15 \mathrm{~km}$ was categorized as rural. Study questionnaire with both closed and open-ended questions was used to gather the required information from the participants. Research assistants who helped to collect the data were trained for two days on the objectives of the study and interview techniques and how to take the anthropometric measurements.

\section{Anthropometrics}


Data collection procedures for this study have already been described elsewhere (Muhihi et al., 2013). Anthropometric measurements were taken early in the morning before classes began. Measurements were conducted in a dedicated room at each school with children wearing light clothes and with no shoes. Body weight was measured using a self-calibrating precision digital scale (Omron, Japan). Height was measured to the nearest $0.1 \mathrm{~cm}$ by a fixed Shorr measuring board (Shorr Productions, Olner, MD). BMI was then calculated as weight in kilogrammes divided by height squared in metres $\left(\mathrm{kg} / \mathrm{m}^{2}\right)$. The Mid-Upper Arm Circumference (MUAC) was measured using a Ribone diameter tape (Ribone Birmingham, UK) accurate to nearest $0.1 \mathrm{~cm}$. An average of three measurements was recorded. All measurements were made while observing standard precautions (Cogill, 2003). The prevalence of overweight and obesity were defined using BMI percentiles. Children with BMI between $85^{\text {th }}$ and $95^{\text {th }}$ percentile for age and sex were considered overweight and children with $\mathrm{BMI}$ at or above $95^{\text {th }}$ percentile were considered obese (Asayama et al., 2003; Olden \& Flegal, 2010).

\section{Socio-demographic information}

A structured questionnaire was used to collect socio-demographic information for the participating children. Important socio-demographic information such as place of residence (rural/urban) age of the child, maternal education, maternal occupation and household size were obtained from parents/guardian during the interview. The questionnaire was pretested in one of the schools which was not selected for the study and following pretesting, all questions which were thought not to be clear were reviewed before the data collection exercise started.

\section{Perception about body size}

Assessment of perception about body size was performed using verbal descriptors. Five levels of verbal description used were "much too thin", "too thin", "just right", "too fat" or "much too fat" (Wardle \& Marsland, 1990; Sands \& Wardle, 2003; Wardle \& Watters, 2004). In this study population of primary schoolchildren, perception about body size was assessed using three levels of verbal descriptors "underweight", "normal for my age" and "overweight or obese" based on the question; "how do you perceive your current body weight?". The researchers supervised data collection daily by checking all questionnaires for completeness and consistence. All errors found were corrected by re-interviewing the child the next day.

\section{Data analysis}

Frequency distributions, summary measures (means, median) and measures of variability were used to describe the general characteristics of the study population. The differences in the perception about one's body weight by all predictor variables were assessed using Chi-square $\left(X^{2}\right)$ tests. Multiple logistic regressions were used to determine individual contribution of predictor variables on favourable body weight perception while adjusting for potential confounding variables. We report Odds Ratios and $95 \% \mathrm{Cl}$ interval. All statistical analyses were performed using Statistical Analysis Software (SAS 9.2, Institute Inc., North Carolina, United States) and adjustment for the cluster effect was done. P-values $\leq 0.05$ were considered statistically significant.

\section{Ethics consideration}

Ethical clearance was obtained from Institutional Review Board of Muhimbili University of Health and Allied Sciences (Ref No. MU/DRP/AEC/VOL.X111/153). Permission to conduct the study was obtained from the education authorities in all the three (Ilala, Kinondoni, Temeke) district councils and head teachers of all involved schools. An informed consent from parent/guardian and assent from the child were obtained prior to participating in the study. Confidentiality of the information collected 
was ensured by using unique participant identification numbers on data collection tools instead of participant name. Completed questionnaires were stored in locked cabinets at Muhimbili University of Health and Allied Sciences and computers which were used for data entry were password coded and nobody who is not part of the study team could access the data files.

\section{Results}

Socio-demographic characteristics

A total of 446 children from nine primary schools in Dar es Salaam were included into the study. Their

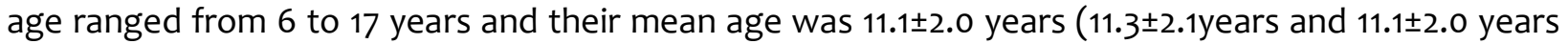
for boys and girls respectively). Most of the children were from urban (55.8\%) and public (88.3\%) schools. Statistically significant sex differences were observed for BMI with girls having higher mean BMI than boys $(P=0.002)$ and education level of the mother $(P=0.0146)$ (Table 1$)$.

Table 1: Socio-demographic characteristics of the study participants

\begin{tabular}{|c|c|c|c|c|}
\hline \multirow[t]{2}{*}{ Variable } & All $(\mathrm{N}=446)$ & \multirow{2}{*}{$\begin{array}{l}\text { Boys }(\mathrm{N}=209) \\
\text { Mean } \pm \text { SD } \quad(\mathrm{n}) \%\end{array}$} & \multirow{2}{*}{$\begin{array}{l}\text { Girls (N=237) } \\
\text { Mean } \pm S D \quad(n) \%\end{array}$} & \multirow[t]{2}{*}{ P-value } \\
\hline & Mean \pm SD (n)\% & & & \\
\hline Age in years & $11.1 \pm 2.0$ & $11.3 \pm 2.1$ & $11.1 \pm 2.0$ & 0.5907 \\
\hline \multicolumn{5}{|l|}{ Place of residence } \\
\hline Rural & $197(44.2)$ & $98(46.9)$ & $99(41.8)$ & \multirow[t]{2}{*}{0.2941} \\
\hline Urban & $249(55.8)$ & $111(53.1)$ & $138(58.2)$ & \\
\hline \multicolumn{5}{|l|}{ Religion } \\
\hline Christian & $225(50.4)$ & $107(51.2)$ & $118(49.8)$ & \multirow[t]{2}{*}{0.7767} \\
\hline Muslim & $221(49.6)$ & $102(48.8)$ & $119(50.2)$ & \\
\hline Number of adults ( $\geq 18 y r s$ ) & $6.2 \pm 2.2$ & $6.3 \pm 2.3$ & $6.2 \pm 2.0$ & 0.9488 \\
\hline Number of children (<18yrs) & $3.2 \pm 2.1$ & $3.0 \pm 1.6$ & $3.3 \pm 2.5$ & 0.3068 \\
\hline \multicolumn{5}{|l|}{ Type of school } \\
\hline Private & $52(11.7)$ & $26(12.4)$ & $26(11.0)$ & \multirow[t]{2}{*}{0.6594} \\
\hline Public & $394(88.3)$ & $183(87.6)$ & $211(89.0)$ & \\
\hline \multicolumn{5}{|l|}{ Ever heard about obesity } \\
\hline Yes & $219(51.0)$ & $106(52.5)$ & $113(49.8)$ & \multirow[t]{2}{*}{0.5772} \\
\hline No & $210(49.0)$ & $96(47.5)$ & $114(50.2)$ & \\
\hline BMI* & $16.6 \pm 4.0$ & $16.1 \pm 4.0$ & $17.0 \pm 4.0$ & 0.0020 \\
\hline
\end{tabular}

*BMI = Body Mass Index

\section{Prevalence of obesity among primary schoolchildren}

The prevalence of overweight and obesity in this population of primary schoolchildren in Dar es Salaam was $9.8 \%$ and $5.2 \%$, respectively. The prevalence of overweight and obesity was significantly higher among girls, $13.1 \%$ and $6.3 \%$ than among their peer boys $6.3 \%$ and $3.8 \%(P=0.0314)$. Overall, the combined prevalence of overweight and obesity was $15.0 \%$ ( $10.1 \%$ among boys and $19.4 \%$ among girls) (Table 2).

Table 2: Prevalence of normal weight, underweight, overweight and obesity among primary school children

\begin{tabular}{lcccl}
\hline Characteristic & All $(\mathbf{N}=\mathbf{4 4 6})$ & Boys $(\mathbf{N}=209)$ & Girls $(\mathbf{N}=237)$ & P-value \\
\hline Underweight & $65(14.6)$ & $36(17.2)$ & $29(12.2)$ & 0.0314 \\
Normal weight & $314(70.4)$ & $152(72.7)$ & $162(68.4)$ & \\
Overweight & $44(9.8)$ & $13(6.3)$ & $31(13.1)$ & \\
Obese & $23(5.2)$ & $8(3.8)$ & $15(6.3)$ & \\
\hline
\end{tabular}




\section{Perception about body weight}

A total of 143 (33.3\%) of the children perceived their body weight as overweight or obese. One hundred eighty-four (42.8\%) perceived their weight as "normal" for their age while 97 (22.5\%) perceived their weight as underweight. Although no significant sex differences were observed on the perception about body weight, more girls (35.9\%) perceived their weight as more overweight/obese than boys (31.3\%).

In the analysis to compare perceived and actual body weight of the children as indicated by BMI, there were significant differences between perceived and actual body weight. Overall, of the 65 overweight and obese children, $64.6 \%$ favourably perceived their weight as overweight or obese while $32.1 \%$ and $3.1 \%$ perceived their body weight as normal and underweight, respectively. Of the 62 underweight children, $43.6 \%$ favourably perceived their weight as underweight while $40.3 \%$ and $16.1 \%$ perceived their weight as normal for age and overweight/obese, respectively.

Among overweight and obese boys ( $n=21)$, majority (61.9\%) favourably perceived their weight as overweight or obese while $28.6 \%$ and $9.5 \%$ perceived their body weight as normal and underweight, respectively. As for overweight and obese girls $(n=44)$, two-thirds $(65.9 \%)$ favourably perceived their weight as overweight or obese while the remaining one third (34.1\%) perceived their body weight as normal and none perceived as underweight. Thirty three boys were underweight and only $37.1 \%$ of them favourably perceived their weight as underweight, $42.9 \%$ perceived as normal and $20.0 \%$ perceived as overweight/obese. Among girls, 27 were underweight and $51.9 \%$ favourably perceived their weight as underweight, 37.0\% perceived as normal and $11.1 \%$ perceived as overweight/obese. The differences between perceived and actual body weight by BMI were statistically significant for both boys and girls (Table 3 ).

Table 3: Comparison between perceived and actual body weight as indicated by body mass index (BMI) among primary schoolchildren

\begin{tabular}{|c|c|c|c|c|}
\hline \multirow[t]{2}{*}{ BMI $\left(\mathrm{kg} / \mathrm{m}^{2}\right)$} & \multicolumn{3}{|c|}{ Perceived body weight } & \multirow[b]{2}{*}{ P-value } \\
\hline & Underweight & Normal weight & Overweight/Obese & \\
\hline All $(n=424)$ & & & & $<0.0001$ \\
\hline Underweight & $27(43.6)$ & $25(40.3)$ & $10(16.1)$ & \\
\hline Normal weight & $68(22.9)$ & $138(46.5)$ & $91(30.6)$ & \\
\hline Overweight/Obese & $2(3.1)$ & $21(32.3)$ & $42(64.6)$ & \\
\hline Boys $(n=201)$ & & & & 0.0054 \\
\hline Underweight & $13(37.1)$ & $15(42.9)$ & $7(20.0)$ & \\
\hline Normal weight & $27(18.6)$ & $75(51.7)$ & $43(29.7)$ & \\
\hline Overweight/Obese & $2(9.5)$ & $6(28.6)$ & $13(61.9)$ & \\
\hline Girls $(n=223)$ & & & & $<0.0001$ \\
\hline Underweight & $14(51.9)$ & $10(37.0)$ & $3(11.1)$ & \\
\hline Normal weight & $41(27.0)$ & $63(41.5)$ & $48(31.5)$ & \\
\hline Overweight/Obese & $0(0.0)$ & $15(34.1)$ & $29(65.9)$ & \\
\hline
\end{tabular}

22 participants ( 8 boys and 14 girls) had missing information on self-perception of their body weight

\section{Factors predicting favourable perception of one's body weight}

Favourable perception of one's body weight was significantly associated with age of the child and area where the school is located. Children aged above 10 years were less likely to have a favourable body weight perception compared to those aged 10 years or less ( $C O R=0.6195 \% \mathrm{Cl} 0.4-0.92)$. The association remained significant even after controlling for sex, school location, type of school and whether the child had ever heard about obesity (AOR=0.55 95\% Cl $0.36-0.88$ ). In Bivariate analysis, children attending urban schools were less likely to have favourable perception about their body 
weights compared to those attending rural schools ( $C O R=0.64955 \mathrm{Cl}=0.44-0.95)$. However this association was not significant after controlling for other predictor variables ( $A O R=0.7195 \% \mathrm{Cl} 0.46$ 1.09) (Table 4).

Table 4: Factors predicting favourable perception of one's body weight

\begin{tabular}{|l|l|l|l|l|}
\hline Variable & Response & $\mathbf{N}$ & COR $(95 \% \mathrm{Cl})$ & AOR $(95 \% \mathrm{CI})$ \\
\hline Age & $<=10$ yrs & 136 & Reference & Reference \\
& $>10 y r s$ & 288 & $0.61(0.40-0.92)$ & O.55(0.36-0.85) \\
\hline Sex & Boys & 201 & Reference & Reference \\
& Girls & 123 & $1.12(0.76-1.63)$ & $1.13(0.76-1.68)$ \\
\hline Area of residence & Rural & 181 & Reference & Reference \\
& Urban & 243 & $0.64(0.44-0.95)$ & $0.71(0.46-1.09)$ \\
\hline Type of school & Public & 51 & Reference & Reference \\
& Private & 373 & $0.57(0.31-1.04)$ & $0.60(0.30-1.18)$ \\
\hline Ever heard about obesity & No & 210 & Reference & Reference \\
& Yes & 219 & $0.85(0.55-1.19)$ & $1.07(0.71-1.61)$ \\
\hline
\end{tabular}

22 participants had missing information on self- perception of their body weight

\section{Discussion}

To our knowledge, this is the first study to investigate perception about body weight using verbal description methods in a representative sample of primary schoolchildren in Tanzania. The combined prevalence of overweight and obesity in this study population was $15.0 \%$. Girls showed higher prevalence (19.4\%) when compared to boys (10.1\%). Our findings on the prevalence of obesity and overweight was relatively higher in comparison to a previous study done in Tanzania (Kruger et al., 2006).

The study has revealed significant differences between perceived body weight and actual size as measured using BMI. There was a tendency towards underestimation of body weight where one-third of overweight and obese children perceived their weight as normal or underweight. Overweight and obese boys underestimated their body weight more than girls. Underweight children on the other hand tend to overestimate their body weight. Our findings are similar to those from other studies which have also reported underestimation of true body weight and is more pronounced among overweight/obese individual (Wardle \& Griffith 2001; Emslie et al., 2001; Brener et al., 2004; Inoue et al., 2007; Johnson-Taylor et al. 2008). Underestimation of one's own weight is associated with increased risk of becoming overweight (Al-Sendi et al., 2004) because they are more likely to attempt to gain weight (Wang et al., 2009).

Western culture has a prevailing perception that low body weight is ideal and attractive (Nichter \& Nichter 1991; Tovee et al., 1998) and is preferred among females (Emslie et al., 2001). Except for a few studies (Duda et al. 2007; Alwan et al., 2011), majority of studies have pointed to the preference of large body size as ideal among black girls ( Caradas et al., 2001; Welch et al., 2004; Holdsworth et al., 2004). There is however a shifting trend towards preference of lean weight especially among people of higher class (Khawaja \& Afifi-Sowed, 2004) and it is increasingly getting promoted through global mass media and/or health awareness campaigns. Boys find a heavier body size ideal, which they associate with physical strength and attractiveness (Maisey et al., 1999). In Tanzania, people's perception about body weight has been greatly influenced by HIV pandemic (Ezekiel et al., 2009). 
Older children were less likely to perceive their body weights favourably than the younger ones. A similar finding was reported by Abalkhail et al. (2014) in a study among schoolchildren and adolescents (9-21 years) in Saudi where overestimation of height and underestimation of weight were found to be more common among children. In our study, children from urban schools were also less likely to have favourable perception about their body weight compared to the children in rural schools.

Our study did not collect information on parents' perception of their children's weight but previous studies had shown that even parents have unfavourable perceptions of their children's body weights. Parent's perception of body size of their children plays a central role in childhood weight management because they are the main gatekeepers of lifestyle changes of their children. Literature has shown that many parents of overweight/obese children do not perceive their children as obese (Young-Hyman et al., 2000; Maynard et al., 2003; Adams et al., 2005; May et al., 2007; Watkins et al., 2007; Gerards et al., 2014). Parents are unlikely to prevent overweight or obesity to their children if the weight status of the child is not perceived as problematic or bearing future adverse health outcomes for their children (Smolak et al., 1999; Young-Hyman et al., 2000). Most parents of overweight /obese children perceive their children as healthy, and may make prevention efforts more difficult.

Our study has some limitations. Its cross-sectional design does not allow drawing inferences on direction of association. Our study did not examine the perception of parents, which is important for weight control interventions in children as they are the main controllers of their children's lifestyle changes. Some strengths of our study include its population based design with a representative sample of children from public and private schools as well as rural, semi-urban and urban settings. Unlike other studies which have relied on self-reported values of weight and height to assess perception of body weight, our study used accurately measured weight and height data.

The prevalence of overweight and obesity in this population of primary school children is not very high. However, more than third of overweight and obese children had unfavourable perception of their body weights. With increasing body of evidence that childhood obesity often persist through adulthood (Garn \& LaVelle, 1985; Field et al., 2005; Rooney et al., 2011), primary schoolchildren is an important group to target with health interventions aiming at modifying risk factors. We recommend health education programmes to primary schoolchildren about overweight, obesity and the associated health effects in order to instil a behaviour of self consciousness on overweight and obesity among children in Tanzania. Routine screening for overweight and obesity among schoolchildren coupled with early and appropriate management may decrease the potential for developing complications later in life.

\section{Competing interests}

The authors declare that they have no competing interests

\section{Authors Contributions}

RNMM Participated in study design and development of the data collection tool, supervised data collection, entry and cleaning. She did data analysis, data interpretation and developed the manuscript. AM, MAN, MM, DN SK, AA and OC participated in study design, development of the data collection tool, supervised data collection and helped with interpretation of the data and review of the manuscript. BL supervised data collection and revised the manuscript. All authors contributed to this manuscript 


\section{Acknowledgements}

The study was funded by Muhimbili University of Health and Allied Sciences through SIDA SAREC capacity building grant. The authors gratefully acknowledge the contribution and participation of schools management, parents, and children who participated in this study.

\section{References}

Abalkhail, B., Shawky, S., \& Soliman, N. (2014) Validity of self-reported weight and height among Saudi school children and adolescents. Saudi Medical Journal 23, 831-837.

Adams, A.K., Quinn, R.A., \& Prince, R.J. (2005) Low recognition of childhood overweight and disease risk among Native-American caregivers. Obesity Research 13, 146-152.

Al-Sendi, A.M., Shetty, P., \& Musaiger, A.O. (2004) Body weight perception among Bahraini adolescents. Child Care Health and Development 30, 369-376.

Alwan, H., Viswanathan, B., Paccaud, F., \& Bovet, P. (2011) Is accurate perception of body image associated with appropriate weight-control behavior among adolescents of the Seychelles. Journal of Obesity 2011, 817242.

Asayama, K., Ozeki, T., Sugihara, S., Keiko, I., Okada, T., \& Hamai., H. (2003) Criteria for medical intervention in obese children: A new definition of "Obesity disease" in Japanese children. Pediatrics International 45, 642-646.

Brener, N.D., Eaton, D.K., Lowry, R. \& Mcmanus, T. (2004) The association between weight perception and BMI among high school students. Obesity Research 12, 1866-1874.

Caradas, A.A., Lambert, E.V. \& Charlton, K.E. (2001) An ethnic comparison of eating attitudes and associated body image concerns in adolescent South African schoolgirls. Journal of Human Nutrition and Dietetics 14, 111-120.

Chillo, P., Lwakatare, J., Janabi, M., Matuja, W. \& Geve, G. (2009) Low prevalence of cardiovascular disease risk factors among primary school children in Tanzania: an opportunity for primordial prevention? Tanzania Medical Journal 24, 9-14.

Cogill, B. (2003) Anthropometric Indicators Measurement Guide. Washington, DC: Food and Nutrition Technical Assistance (FANTA) Project, FHI 360.

Darshini, D.K. \& Rajesh, J. (2013) Body weight perception and weight control practices among teenagers. ISRN Nutrition. http://dx.doi.org/10.5402/2013/395125

De Onis, M., Blössner, M. \& Borghi, E. (2010) Global prevalence and trends of overweight and obesity among preschool children. American Journal of Clinical Nutrition 92, 1257-1264.

Duda, R.B., Jumah, N.A., Hill, A.J., Seffah, J. \& Biritwum, R. (2007) Assessment of the ideal body image of women in Accra, Ghana. Tropical Doctor 37, 241-244.

Emslie, C., Hunt, K. \& Macintyre, S. (2001) Perceptions of body image among working men and women. Jounal of Epidemiology and Commununity Health 55, 406-407.

Ezekiel, M.J., Talle A., Juma, J.M., \& Klepp, K. (2009) "When in the body, it makes you look fat and HIV negative": the constitution of antiretroviral therapy in local discourse among youth in Kahe, Tanzania. Social Science \& Medicine 68, 957-964.

Field, A.E., Cook, N.R. \& Gillman, M.W. (2005) Weight status in childhood as a predictor of becoming overweight or hypertensive in early adulthood. Obesity Research 13, 163-169.

Garn, S.M. \& LaVelle, M. (1985) Two-decade follow-up of fatness in early childhood. American Journal of Diseases of Children 139, 181-185.

Gerards, S.M., Gubbels, J.S., Dagnelie, P.C., Kremers, S.P., Stafleu, A., de Vries., N.K. \& Thijs, C. (2014) Parental perception of child's weight status and subsequent BMIz change: the KOALA birth cohort study. BMC Public Health 14, 291. 
Gillum, R. \& Sempos, C.T. (2005) Ethnic variation in validity of classification of overweight and obesity using self-reported weight and height in American women and men: the Third National Health and Nutrition Examination Survey. Nutrition Journal 4, 27.

Holdsworth, M., Gartner, A., Landais, E., Maire, B. \& Delpeuch, F. (2004) Perceptions of healthy and desirable body size in urban Senegalese women. International Journal of Obesity and Related Metabolic Disorders 28, 1561-1568.

Inoue, M., Toyokawa, S. \& Miyoshi, Y. (2007) Degree of agreement between weight perception and body mass index of Japanese workers: MY health up study. Journal of Occupational Health 49, 379-381.

Johnson, F., Cooke, L., Croker, H. \& Wardle, J. (2008) Changing perceptions of weight in Great Britain: comparison of two population surveys. British Medical Journal 337, 494.

Johnson-Taylor, W.L., Fisher, R.A., Hubbard, V.S., Starke-Reed, P. \& Eggers, P.S. (2008) The change in weight perception of weight status among the overweight: comparison of NHANES III (19881994) and 1999-2004 NHANES. The International Journal of Behavioral Nutrition and Physical Activity 5, 9.

Kafyulilo, A.C. \& Mafumiko, F.M. (2010) Prevalence of overweight and obesity among primary school children in Tanzania: Experiences from Kinondoni and Njombe Districts. (http://ssrn.com/abstract=1630534)

Khawaja, M. \& Afifi-Sowed, R.A. (2004) Images of body weight among young men and women: evidence from Beirut, Lebanon. Journal of Epidemiology and Community Health 58, 352-353.

Kruger, R., Kruger, H. \& Macintyre, U. (2006) The determinants of overweight and obesity among 10to 15-year-old school children in the North West Province, South Africa - the THUSA BANA (Transition and Health during Urbanisation of South Africans; BANA, children) study. Public Health Nutrition 9, 351-358.

Maisey, D.S., Vale, E.L., Cornelissen, P.L. \& Tovee , M.J. (1999) Characteristics of male attractiveness for women. Lancet 353, 1500.

May, A.L., Donohue, M., Scanlon, K.S., Sherry, B., Dalenius, K., Faulkner, P. \& Birch, L.L. (2007) Childfeeding strategies are associated with maternal concern about children becoming overweight, but not children's weight status. Journal of the American Dietetic Association 107, 1167-1175.

Maynard, L.M., Galuska, D.A., Blanck, H.M. \& Serdula, M.K. (2003) Maternal perceptions of weight status of children. Pediatrics 111, 1226-1231.

Mosha, T.C.E. \& Fungo, S. (2010) Prevalence of overweight and obesity among children aged 6-12 years in Dodoma and Kinondoni municipalities, Tanzania. Tanzania Journal of Health Research 12, 6-16.

Muhihi, A., Njelekela, M., Mpembeni, R., Mwiru, R., Mligiliche, N. \& Mtabaji, J. (2012) Obesity, overweight and perceptions about body weight among middle-aged adults in Dar es Salaam, Tanzania. ISRN Obesity 2012, 368520.

Muhihi, A.J., Mpembeni, R.N., Njelekela, M.A., Anaeli, A., Chillo, O., Kubhoja, S., Lujani, B., Maghembe, M. \& Ngarashi, D. (2013) Prevalence and determinants of obesity among primary school children in Dar es Salaam, Tanzania. Archives of Public Health 71, 26.

Nichter, M. \& Nichter, M. (1991) Hype and weight. Special Issue: Bigger is better? Biocultural dynamics of body shape. Medical Anthropology 13, 249-284.

Olden, C. \& Flegal, K. (2010) Changes in terminology for childhood overweight and obesity. National Health Statistics Reports 25, 1-5.

Paeratakul, S., White, M.A., Williamson, D.A., Ryan, D.H. \& Bray, G.A. (2002) Sex, race/ethnicity, socioeconomic status, and BMI in relation to self-perception of overweight. Obesity Research 10, 345-350. 
Rooney, B.L., Mathiason, M.A. \& Schauberger, C.W. (2011) Predictors of obesity in childhood, adolescence, and adulthood in a birth cohort. Maternal and Child Health Journal 15, 1166-1175.

Sands, E.R. \& Wardle, J. (2003) Internalization of ideal body shapes in 9-12-year-old girls. The International Journal of Eating Disorders 33, 193-204.

Smolak, L. (2004) Body image in children and adolescent: where do we go from here? Body Image 1, 15-28.

Smolak, L., Levine, M.P. \& Schermer, F. (1999) Parental input and weight concerns among elementary school children. The International Journal of Eating Disorders 25, 263-271.

Tovee, M.J., Reinhardt, S., Rmery, J.L. \& Cornelissen, P.L. (1998) Optimum body-mass index and maximum sexual attractiveness. Lancet, 352, 548.

Truby, H. \& Paxton, S.J. (2002) Development of the children's body image scale. The British Journal of Clinical Psychology 41, 89-97.

Truby, H. \& Paxton, S.J. (2008) The children's body image scale: reliability and use with international standards for body mass index. The British Journal of Clinical Psychology 47, 119-124.

Vander Wal, J.S. \& Thelen, M.H. (2000) Eating and body image concerns among obese and averageweight children. Addictive Behaviors 25, 775-778.

Wang, Y., Liang, H. \& Chen, X. (2009) Measured body mass index, body weight perception, dissatisfaction and control practices in urban, low-income African American adolescents. BMC Public Health 9, 183.

Wardle, J. \& Griffith, J. (2001) Socioeconomic status and weight control practices in British adults. Journal of Epidemiology and Community Health 55, 185-190.

Wardle, J. \& Marsland, L. (1990) Adolescent concerns about weight and eating; a social-development perspective. Journal of Psychosomatic Research 34, 377-391.

Wardle, J. \& Watters, R. (2004) Sociocultural influences on attitudes to weightand eating: results of a natural experiment. The International Journal of Eating Disorders 35, 589-596.

Watkins, M.G., Clark, K.M., Foster, C.M., Welch, K.B. \& Kasa-Vubu, J.Z. (2007) Relationships among body mass index, parental perceptions, birthweight and parental weight after referral to a weight clinic. Journal of the National Medical Association 99, 908-913.

Welch, C., Gross, S.M., Bronner, Y., Dewberry-Moore, N. \& Paige, D.M. (2004) Discrepancies in body image perception among fourth-grade public school children from urban, suburban, and rural Maryland. Journal of the American Dietetic Association 104, 1080-1085.

Young-Hyman, D., Herman, L.J., Scott, D.L. \& Schlundt, D.G. (2000) Care giver perception of children's obesity-related health risk: a study of African American families. Obesity Research 8, 241-248. 